$551.551: 551.552: 551.553$

\title{
Similarity between Natural Wind in the Atmosphere and Model Wind in a Wind Tunnel
}

- Modeling Criteria for a Local Wind -

by

\author{
S. Nemoto \\ Meteorological Research Institute, Tokyo \\ (Received August 31, 1962)
}

\section{Part IV. Supplement to the Theoretical Treatment}

\begin{abstract}
In the present paper various conditions for modeling which have not been sufficiently discussed in the previous paper (Part I) are examined, and the relative position of the condition for similarity, $U_{\infty_{M}} / U_{\infty_{N}}=$ $\left(L_{M} / L_{N}\right)^{\frac{1}{3}}$, proposed in the previous paper, is described. Moreover, some obscure points in the previous paper are made clear.
\end{abstract}

\section{Introduction}

Such a limited case as is easily realized in an ordinary wind tunnel was dealt with in our first report (Part I). It was a simple case satisfying the following conditions :

(i) the reference region is comparatively small, hence the effect of the rotation of the earth is negligible,

(ii) the variation of static pressure with height may be neglected,

(iii) the effect of gravity is negligible,

(iv) the effect of the thermal stratification of the atmosphere is negligible,

(v) the effect of compressibility of the air is negligible, and, furthermore,

(vi) the molecular viscosity is negligibly small in comparison with the eddy viscosity.

In the present paper we want to examine the effect of the rotation of the earth and the effect of gravity and make clear the relative position of the condition for similarity, $U_{\infty M} / U_{\infty N}=\left(L_{M} / L_{N}\right)^{\frac{1}{3}}$, proposed in the previous paper.

Now, as shown in the text-book of hydrodynamics, if all five quantities, that is, three kinematical quantities $\mathrm{u}, \mathrm{v}, \mathrm{w}$ and two physical quantities $p, \rho$ (as known from thermodynamics, two quantities vary independently) can be obtained at each point of a field of flow, the state of the flow will be determined completely. Therefore, five equations are required in order to obtain these five quantities. This expectation may be realized definitely by the following five equations, that is, the equations of motion, of continuity and of state. Therefore, the similarity problem of 
the flow may be dealt with on the basis of these five equations. That is, if the conditions that each term of the five non-dimensional equations derived from these five equations by using representative quantities (for example, representative length and representative wind velocity) remains numerically invariant in both flows of model and prototype would be found, these conditions might be considered to be those to be required. These treatments have been summarized by BiRkHoff (1950) in his book "Hydrodynamics". In his work gravity and molecular viscosity have been taken into account, but kinetic viscosity (that is, turbulence) and the effect of the rotation of the earth have been left out of consideration.

D. Fultz (1951) has theoretically dealt with the problem of similarity under consideration of the effect of the rotation of the earth and has obtained the results that when the Reynolds number, the Froude number and the Rossby number of the model flow are identical with those of the natural flow, respectively, the two flows are similar to one another. (Whether these conditions are simultaneously satisfied or not has not been examined). The turbulence, however, was not taken into account in his study.

When the scale of a phenomenon to be dealt with is small, the Coriolis force and the variation of static pressure (variation of the air density $\rho$ ) might be left out of consideration, but the fact that the flow is turbulent cannot be neglected. Therefore, it is evident that the turbulence by all means must be taken into account when the model experiment on the natural wind is dealt with.

K. Takahashi (1944) dealt with the problem of model experiment under consideration of the eddy diffusivity as described in the first report, and was followed by $\mathrm{E}$. InOuE $(1948,1951,1952)$ who dealt with this problem on the basis of the concept with respect to the turbulent diffusion. He proposed the substitution of the similarity law of turbulent diffusion phenomena for the similarity law of model experiment in a wind tunnel and adopted the following conditions as the similarity conditions, as already described in the first report; that is, identity of the intensities of turbulence and identity of the turbulon Reynolds numbers. It is, however, impossible to know, from these two conditions only, whether the structures of turbulence of the two flows to be compared are similar or not, as will be discussed in the following section.

Now, it will be called into question whether we can find conditions under which the five non-dimensional equations previously described (equations of motion, of continuity and of state) have identical numerical terms regardless of the absolute size of the system to which they are applied and whether, when those conditions should be formally found, modeling satisfying those conditions can in fact be experimentally realized or not. 'For example, even if the equations of motion only are called into question, exclusive of the two other equations, its modeling is, unfortunately, experimentally more difficult to realize, as far as these equations are expressed in the forms as complete as possible. Therefore, we must now satisfy ourselves with the approximate similarity obtained from neglecting ineffective terms the orders of which are negligibly small in comparison with those of the other terms of the equations of motion. These things will be described concretely in the following sections. In the present paper the similarity problem is dealt with especially in consideration of the turbulence. 


\section{Modeling in which the turbulence is left out of consideration}

There has been modeling of D. FuLTz (1951) with respect to that of the largescale natural wind in the case where the turbulence is left out of consideration. That is, FulTz has proposed the similarity conditions in the following way, taking account of the two effects of the rotation of the earth and gravity, and further molecular viscosity alone.

First, the equation of motion on the rotating earth may be expressed as follows:

$$
\frac{\partial v}{\partial t}+v \cdot \nabla v+2 \Omega \times v=-\alpha \nabla p-g i+\nu\left[\nabla^{2} v+\frac{1}{3} \nabla(\Delta \cdot v)\right],
$$

where

$\boldsymbol{\Omega}:$ the basic rotation vector of the coordinate frame,

$\alpha: 1 / \rho$ a specific volume,

$p$ : pressure,

$\nu$ : molecular kinematic viscosity,

$\boldsymbol{i}$ : a unit vector upward, perpendicular to geopotential surfaces,

$v$ : a velocity vector.

This is the Navier-Stokes equation of classical hydrodynamics, written for a relative frame.

Next, reference quantities (constant for a given system) have been chosen as follows :

$U:$ a relative velocity,

$\Omega$ : the magnitude of the basic rotation of the coordinate frame,

$A$ : the radius of the earth (or model sphere),

$D$ : a reference density,

and then non-dimensional variables and operators have been defined as follows:

$$
\left\{\begin{aligned}
v^{\prime} & =\frac{v}{U}, \\
t^{\prime} & =\Omega t, \\
p^{\prime} & =\frac{p}{D U^{2}}, \\
\alpha^{\prime} & =\alpha D, \\
\nabla^{\prime} & =A \nabla, \\
\nabla^{\prime 2} & =A^{2} \nabla^{2},
\end{aligned}\right.
$$

where $p^{\prime}$ is the pressure coefficient used in similar analyses in aerodynamics (GoLdsTEIN, 1938: BirkHofF, 1950).

Then, by dividing by $A / U^{2}$ after converting each term of eq. (2.1) to primed variables by multiplying them by $A / \Omega U^{3}$, one obtains

$$
\frac{\partial \boldsymbol{v}^{\prime}}{\partial t^{\prime}}+2 \hat{\boldsymbol{\Omega}} \times \boldsymbol{v}^{\prime}=-\left(\alpha^{\prime} \nabla^{\prime} \boldsymbol{p}^{\prime}+\boldsymbol{v}^{\prime} \cdot \nabla \boldsymbol{v}^{\prime}\right) U^{2} / A \Omega U-g \boldsymbol{i} / \Omega U+\left[\nabla^{\prime 2} \boldsymbol{v}^{\prime}+\frac{1}{3} \nabla^{\prime}\left(\nabla^{\prime} \cdot \boldsymbol{v}^{\prime}\right)\right] \nu / A^{2} \Omega,
$$


where $\hat{\boldsymbol{\Omega}}$ denotes a non-dimensional unit vector, parallel to the basic rotation vector.

Then in order to follow the established notation as closely as possible, one defines

$$
\begin{array}{ll}
R_{c}=U A / \nu & \text { the Reynolds number, } \\
F=U^{2} / g A & \text { the Froude number, } \\
R_{0}=U / A \Omega & \text { the Rossby number. }
\end{array}
$$

Then, eq. (2.3) may be rewritten as

$$
\frac{\partial \boldsymbol{v}^{\prime}}{\partial t^{\prime}}+2 \hat{\boldsymbol{\Omega}} \times \boldsymbol{v}^{\prime}=-\left(\alpha^{\prime} \nabla^{\prime} p^{\prime}+\boldsymbol{v}^{\prime} \cdot \nabla^{\prime} \boldsymbol{v}^{\prime}\right) R_{0}-i R_{0} / F+\left[\nabla^{\prime 2} \boldsymbol{v}^{\prime}+\frac{1}{3} \nabla^{\prime}\left(\nabla^{\prime} \cdot \boldsymbol{v}^{\prime}\right)\right] R_{0} / R_{c}
$$

Therefore, the non-dimensional equation of motion with identical numerical terms regardless of the absolute size of the system to which it is applied, contains, in the form of this example, three parameters only: $R_{e}, F, R_{0}$. Hence, the conditions for dynamic similarity between a geometrically similar model and the prototype become, so far as the equation of motion alone is concerned, simply the identity of each of the three parameters $R_{c}, F, R_{0}$, formed from reference quantities in model and prototype, respectively.

Next, the equations of continuity, of state and furthermore boundary and initial conditions have to be considered. However, no new parameter is introduced from the equation of continuity and the most ordinary types of non-dimensional boundary and initial conditions, as Fultz has described.

The pressure, density and temperature of the atmosphere vary with height in such large-scale atmospheric phenomena as Fultz has dealt with. But no method of reproducing this state of the atmosphere in a similar form on a small scale has been known yet.

Let us now consider about the conditions obtained by FuLTz, that is, the conditions of identity for the parameters $R_{e}, F$ and $R_{0}$, formed from reference quantities in model and prototype, respectively. First, the condition of identity for the Reynolds number may be represented by

$$
\frac{U_{M} A_{M}}{\nu_{M}}=\frac{U_{N} A_{N}}{\nu_{N}}
$$

where the suffix $M$ of the variables signifies that these variables refer to the quantities on a model experiment in a wind tunnel, and the suffix $N$ that these variables refer to the quantities on a natural flow. On the other hand, the condition of identity for the Froude number may be represented by

$$
\frac{U^{2}{ }_{M}}{g_{M} A_{M}}=\frac{U^{2}{ }_{N}}{g_{N} A_{N}}
$$

Then from these two relations

$$
\frac{A_{M}}{A_{N}}=\left(\frac{g_{N}}{g_{M}}\right)^{\frac{1}{3}}\left(\frac{\nu_{M}}{\nu_{N}}\right)^{\frac{2}{3}}
$$


may be obtained. If $g_{N}$ and $\nu_{N}$ are known and the reduced scale of the model $A_{M} / A_{N}$ is determined, the corresponding $g_{M}$ and $\nu_{M}$ should be determined to satisfy the above relation (2.7). But it is experimentally very difficult to give a suitable value to $g_{M}$. So that in this case it is very difficult that the condition of identity for $R_{e}$ and that for $F$ are simultaneously satisfied. Therefore, it seems that the model experiment on the large-scale atmospheric phenomenon would be impossible under these treatments.

Turbulence has not been considered in such treatment as Fultz's, that is, the flow has been dealt with as laminar flow. But the natural wind, as is well known, is turbulent, and so turbulence must be taken into account in dealing with the model experiment on it. Each order of each term of the equation of motion is as shown in the following :

\begin{tabular}{|c|c|c|c|}
\hline \multirow{2}{*}{ Term } & \multicolumn{2}{|c|}{ Order } & \multirow{2}{*}{ Dimension } \\
\hline & Horizontal & Vertical & \\
\hline$\frac{\partial v}{\partial t}$ & $10^{-2}$ & & $\mathrm{~cm} \cdot \mathrm{sec}^{-2}$ \\
\hline$v \cdot \Gamma v$ & $10^{-2}$ & & $" \prime$ \\
\hline $\boldsymbol{\Omega} \times \boldsymbol{v}$ & $10^{-1}$ & & " \\
\hline$\alpha \nabla p$ & $10^{-1}$ & & " \\
\hline$g \hat{i}$ & negligibly small & $10^{3}$ & " \\
\hline$\nu\left[\nabla^{2} \boldsymbol{v}+\frac{1}{3} \Gamma(V) \boldsymbol{v}\right]$ & $10^{-14}$ & & " \\
\hline
\end{tabular}

This is an example and applied to the phenomenon which covers the region with length scales of $10^{6} \mathrm{~m}$ and $10^{4} \mathrm{~m}$ in the horizontal and vertical directions, respectively, and has a propagation velocity of about $10 \mathrm{~m} / \mathrm{sec}$. The term of molecular viscosity, as seen from this result, is very small. This may be considered to be due to the fact that it has been estimated in the synoptic scale, that is, the averaging time which has been taken for the estimation of the wind velocity is long and that the distance which has been taken for the estimation of the velocity gradient is very large. Therefore, if its distance and averaging time are smaller than they this term will have a larger value than that shown in this table, though its order will be small in comparison with those of the other terms. But, if $\nu$ is replaced with the eddy diffusion coefficient $K$, a value of $K$ on the phenomenon with a length scale of $10^{6} \mathrm{~m}$ amounts to $10^{11} \mathrm{~cm}^{2} / \mathrm{sec}$, hence the order of $K\left[\nabla^{2} v+\frac{1}{3} \nabla(\nabla v)\right]$ reaches $10^{-2}$ and it may not be neglected in comparison with the other terms. That is, the effect of the turbulence must be taken into account in the case of the natural wind, as described above.

From what has been described above, the modeling of FuLTz may be considered to be practically unrealizable by the model experiment in the wind tunnel usually used.

\section{Modeling in which turbulence is taken into consideration}

As model experiment on the atmospheric phenomena of large scale has been considered to be very difficult at the present time as described in the previous section (2), we now want to consider a model experiment of a small-scale phenomenon in 
which variations of static pressure and density of the air with height may be neglected, that is, the equation of state may be left out of consideration. The equations of motion and of continuity are to be called into question in this case, but as no new condition is introduced from the equation of continuity, in fact, the equation of motion only may be considered. But, turbulence must be by all means taken into account. Therefore, we here consider the equation of motion of the mean flow in the turbulent flow field of the natural wind. Let us now take the $x$ axis to the east, the $y$ axis to the north and the $z$ axis to the vertical direction, respectively. Then, $\Omega_{x}=0$ will hold. Therefore, the equations of motion may be represented in this case as follows, provided that the fluid is incompressible,

$$
\begin{aligned}
\frac{\partial U}{\partial t} & +\frac{\partial}{\partial x}\left(U^{2}\right)+\frac{\partial}{\partial x}\left(\bar{u}^{2}\right)+\frac{\partial}{\partial y}(U V)+\frac{\partial}{\partial z}(U W) \\
& =g_{x}-2\left(\Omega_{y} W-\Omega_{z} U\right)-\frac{1}{\rho} \frac{\partial p}{\partial x}+\frac{\partial}{\partial y}\left(K_{y} \frac{\partial U}{\partial y}\right)+\frac{\partial}{\partial z}\left(K_{z} \frac{\partial U}{\partial z}\right) \\
& +\nu\left(\frac{\partial^{2} U}{\partial x^{2}}+\frac{\partial^{2} U}{\partial y^{2}}+\frac{\partial^{2} U}{\partial z^{2}}\right), \\
\frac{\partial V}{\partial t}+ & \frac{\partial}{\partial x}(U V)+\frac{\partial}{\partial y}\left(V^{2}\right)+\frac{\partial}{\partial y}\left(\bar{v}^{2}\right)+\frac{\partial}{\partial z}(V W) \\
& =g_{y}-2 \Omega_{z} U-\frac{1}{\rho} \frac{\partial p}{\partial y}+\frac{\partial}{\partial x}\left(K_{x} \frac{\partial V}{\partial x}\right)+\frac{\partial}{\partial z}\left(K_{z} \frac{\partial V}{\partial z}\right) \\
& +\nu\left(\frac{\partial^{2} V}{\partial x^{2}}+\frac{\partial^{2} V}{\partial y^{2}}+\frac{\partial^{2} V}{\partial z^{2}}\right), \\
\frac{\partial W}{\partial t} & +\frac{\partial}{\partial x}(U W)+\frac{\partial}{\partial y}(V W)+\frac{\partial}{\partial z}\left(W^{2}\right)+\frac{\partial}{\partial z}\left(\bar{w}^{2}\right) \\
& =g_{z}+2 \Omega_{y} U-\frac{1}{\rho} \frac{\partial p}{\partial z}+\frac{\partial}{\partial x}\left(K_{x} \frac{\partial W}{\partial x}\right)+\frac{\partial}{\partial y}\left(K_{y} \frac{\partial W}{\partial y}\right) \\
& +\nu\left(\frac{\partial^{2} W}{\partial x^{2}}+\frac{\partial^{2} W}{\partial y^{2}}+\frac{\partial^{2} W}{\partial z^{2}}\right),
\end{aligned}
$$

where

$U, V, W:$ the $x, y, z$ components of mean wind velocity,

$u, v, w$ : the $x, y, z$ components of turbulent velocity,

$\Omega_{x}, \Omega_{y}, \Omega_{z}$ : the $x, y, z$ components of angular velocity of the rotation of the earth, $\rho:$ the density of the air,

$K_{x}, K_{y}, K_{z}$ : eddy diffusion coefficients in the $x, y, z$ directions,

$\nu:$ the molecular viscosity coefficient of the air,

$g_{x}, g_{y}, g_{z}$ : the $x, y, z$ components of the acceleration of gravity.

As the phenomena to be dealt with here are of fairly small scale, the Coriolis force may be left out of consideration and the terms on the molecular viscosity may also be neglected as being small in comparison with the terms on the eddy viscosity. Furthermore, it may be considered that both $g_{x}$ and $g_{y}$ are equal to 0 and $g_{z}=-g$ (the direction of the $z$ axis is upward). Thus the equations described above may be rewritten as follows: 
(3. 4)

$$
\begin{aligned}
\frac{\partial U}{\partial t} & +\frac{\partial}{\partial x}\left(U^{2}\right)+\frac{\partial}{\partial x}\left(\bar{u}^{2}\right)+\frac{\partial}{\partial y}(U V)+\frac{\partial}{\partial z}(U W) \\
& =-\frac{1}{\rho} \frac{\partial p}{\partial x}+\frac{\partial}{\partial y}\left(K_{y} \frac{\partial U}{\partial y}\right)+\frac{\partial}{\partial z}\left(K_{z} \frac{\partial U}{\partial z}\right), \\
\frac{\partial V}{\partial t} & +\frac{\partial}{\partial x}(U V)+\frac{\partial}{\partial y}\left(V^{2}\right)+\frac{\partial}{\partial y}\left(\bar{v}^{2}\right)+\frac{\partial}{\partial z}(V W) \\
& =-\frac{1}{\rho} \frac{\partial p}{\partial y}+\frac{\partial}{\partial x}\left(K_{x} \frac{\partial V}{\partial x}\right)+\frac{\partial}{\partial z}\left(K_{z} \frac{\partial V}{\partial z}\right), \\
\frac{\partial W}{\partial t} & +\frac{\partial}{\partial x}(U W)+\frac{\partial}{\partial y}(V W)+\frac{\partial}{\partial z}\left(W^{2}\right)+\frac{\partial}{\partial z}\left(\bar{w}^{2}\right) \\
& =-g-\frac{1}{\rho} \cdot \frac{\partial p}{\partial z}+\frac{\partial}{\partial x}\left(K_{x} \frac{\partial W}{\partial x}\right)+\frac{\partial}{\partial y}\left(K_{y} \frac{\partial W}{\partial y}\right) .
\end{aligned}
$$

Let us now define, as in section 2 , the non-dimensional variables as follows:

$$
\left\{\begin{aligned}
(x, y, z) & =L \times\left(x^{\prime}, y^{\prime}, z^{\prime}\right) \\
(U, V, W) & =U_{\infty} \times\left(U^{\prime}, V^{\prime}, W^{\prime}\right) \\
t & =\frac{L}{U_{\infty}} \times t^{\prime} \\
\rho & =\rho_{0} \times \rho^{\prime}\left(\rho_{0}: \text { reference density }\right) \\
\frac{p}{\rho_{0} U_{\infty}^{2}} & =p^{\prime}
\end{aligned}\right.
$$

where $L$ and $U_{\infty}$ denote, respectively, the representative length (e.g. height of a mountain) and the representative uniform velocity. Then the equations of motion may be rewritten as follows by using the relations (3.7) :

$$
\begin{gathered}
\frac{\partial U^{\prime}}{\partial t^{\prime}}+\frac{\partial}{\partial x^{\prime}}\left(U^{\prime 2}\right)+\frac{\partial}{\partial x^{\prime}}\left(\frac{\bar{u}^{2}}{U_{\infty}^{2}}\right)+\frac{\partial}{\partial y^{\prime}}\left(U^{\prime} V^{\prime}\right)+\frac{\partial}{\partial z^{\prime}}\left(U^{\prime} W^{\prime}\right) \\
=-\frac{1}{\rho^{\prime}} \frac{\partial p^{\prime}}{\partial x^{\prime}}+\frac{\partial}{\partial y^{\prime}}\left\{\left(\frac{K_{y}}{L U_{\infty}}\right) \frac{\partial U^{\prime}}{\partial y^{\prime}}\right\}+\frac{\partial}{\partial z^{\prime}}\left\{\left(\frac{K_{z}}{L U_{\infty}}\right) \frac{\partial U^{\prime}}{\partial z^{\prime}}\right\}, \\
\frac{\partial V^{\prime}}{\partial t^{\prime}}+\frac{\partial}{\partial x^{\prime}}\left(U^{\prime} V^{\prime}\right)+\frac{\partial}{\partial y^{\prime}}\left(V^{\prime 2}\right)+\frac{\partial}{\partial y^{\prime}}\left(\frac{\bar{v}^{2}}{U^{2}}\right)+\frac{\partial}{\partial z^{\prime}}\left(V^{\prime} W^{\prime}\right) \\
=-\frac{1}{\rho^{\prime}} \frac{\partial p^{\prime}}{\partial y^{\prime}}+\frac{\partial}{\partial x^{\prime}}\left\{\left(\frac{K_{x}}{L U_{\infty}}\right) \frac{\partial V^{\prime}}{\partial x^{\prime}}\right\}+\frac{\partial}{\partial z^{\prime}}\left\{\left(\frac{K_{z}}{L U_{\infty}}\right) \frac{\partial V^{\prime}}{\partial z^{\prime}}\right\}, \\
\frac{\partial W^{\prime}}{\partial t^{\prime}}+\frac{\partial}{\partial x^{\prime}}\left(U^{\prime} W^{\prime}\right)+\frac{\partial}{\partial y^{\prime}}\left(V^{\prime} W^{\prime}\right)+\frac{\partial}{\partial z^{\prime}}\left(W^{\prime 2}\right)+\frac{\partial}{\partial z^{\prime}}\left(\frac{\bar{w}^{2}}{U_{\infty}^{2}}\right) \\
=-g \frac{L}{U_{\infty}^{2}}-\frac{1}{\rho^{\prime}} \frac{\partial p^{\prime}}{\partial z^{\prime}}+\frac{\partial}{\partial x^{\prime}}\left\{\left(\frac{K_{x}}{L U_{\infty}}\right) \frac{\partial W^{\prime}}{\partial x^{\prime}}\right\}+\frac{\partial}{\partial y^{\prime}}\left\{\left(\frac{K_{y}}{L U_{\infty}}\right) \frac{\partial W^{\prime}}{\partial y^{\prime}}\right\} .
\end{gathered}
$$

In order that the two flows of model and prototype may become similar, each term of the above-mentioned equations must be numerically identical for the two cases. Let us now denote the quantities relevant to the model wind by attaching the 
suffix $M$ and those relevant to the natural wind by the suffix $N$, then the condition for dynamic similarity is that the relations

$$
\begin{aligned}
& \text { (3.11) } \frac{\bar{u}_{M}^{2}}{U_{\infty M}^{2}}=\frac{\bar{u}^{2}{ }_{N}}{U^{2}{ }_{\infty N}}, \quad \frac{\bar{v}^{2}{ }_{M}}{U^{2}{ }_{\infty M}}=\frac{\bar{v}^{2}{ }_{N}}{U^{2}{ }_{\infty N}}, \quad \frac{\bar{v}^{2}{ }_{M}}{U^{2}{ }_{\infty M}}=\frac{\bar{v}^{2}{ }_{N}}{U^{2}{ }_{\infty N}}, \\
& \text { (3.12) } \frac{K_{x M}}{L_{M} U_{\infty M}}=\frac{K_{x N}}{L_{N} U_{\infty N}}, \quad \frac{K_{y M}}{L_{M} U_{\infty M}}=\frac{K_{y N}}{L_{N} U_{\infty N}}, \quad \frac{K_{z M}}{L_{M} U_{\infty M}}=\frac{K_{z N}}{L_{N} U_{\infty N}}, \\
& \text { (3.13) } \frac{g_{M} L_{M}}{U_{\infty}^{2}}=\frac{g_{N} L_{N}}{U_{\infty \infty N}^{2}},
\end{aligned}
$$

are simultaneously satisfied, provided that the model is geometrically similar to the prototype. Then (3.11) shows the identity of the intensities of turbulence at corresponding places of the two flows, and (3.12) shows the identity of the eddy Reynolds numbers at corresponding places. The relation (3.13) shows the identity of the Froude numbers, and this condition expresses the effect of gravity and seems to have to be taken into account in the case where a vertical acceleration due to an intense convective motion exists, even if the reference region is fairly small. As $g_{M}$, in general, is nearly equal to $g_{N}$, it follows from the relation (3.13) that

$$
\text { (3.14) } \frac{U^{2}{ }_{\infty M}}{U_{\infty N}^{2}}=\frac{L_{M}}{L_{N}} \text {. }
$$

Hence, if the reduced scale of the model is determined, $U_{\infty M}$ corresponding to $U_{\infty N}$ is uniquely determined from this condition and cannot be chosen arbitrarily.

Therefore, it will next be necessary to consider whether the two other conditions, (3.11) and (3.12), can be simultaneously satisfied or not under this condition. Since the conditions (3.11) and (3.12) contain the quantities relevant to turbulence, it is necessary to consider its structure.

In general, a turbulence may be considered to consist of a great number of eddies which are superposed upon each other. So, when an eddy the size and the velocity of which are $\Lambda_{n}$ and $V_{n}$, respectively, is considered, a number of eddies with sizes smaller than $A_{n}$ ( $n$ denotes rank of eddy) are contained in this eddy and $V_{n}$ may be expected to become smaller with increase of $n$; hence the relation between $V_{n}$ and $V_{n+1}$ may be supposed to be given by

$$
V_{n+1}=\zeta V_{n},
$$

$\zeta<1$ must hold. If an eddy of the size $\Lambda_{n}$ exists in an inertial subrange which contains eddies of sizes far smaller than that of the largest eddy and far larger than that of the smallest eddy, provided that the flow is isotropic and stationary, the relation between velocity and size of an eddy in this range must be determined solely by the average rate of dissipation of energy per unit mass and per unit time of the fluid $\varepsilon$ according to Kolmogoroff's second similarity hypothesis (1941), which is applied to a locally homogeneous turbulence. Hence, $\zeta$ is considered to be constant independent of $n$ in any case, irrespective of either natural wind or model wind. Therefore, the total energy contained within $V_{n}$ is given by

$$
V^{2}+V^{2}{ }_{n+1}+V^{2}{ }_{n+2}+\cdots \cdots
$$




$$
=\frac{1}{1-\zeta^{2}} V_{n}^{2}, \quad \text { (approximately) }
$$

and proportional to $V^{2}{ }_{n}$. On the other hand, when the wave-number per unit length $k_{n}$ is considered in place of an eddy size $A_{n}$, regarding the spatial distribution of eddies as a kind of expression of wave motion, $k_{n}$ cs $1 / \Lambda_{n}$, that is, $k_{n}$ is inversely proportional to $A_{n}$, and the fluctuation energy contained within the wave-number range between $k$ and $k+d k$ may be proportional to

$$
\bar{V}^{2} F(k) d k,
$$

where $\bar{V}^{2}$ denotes the average level of the turbulent energy, then the total energy of all eddies with wave-numbers larger than $k_{n}$ may be proportional to

$$
\bar{V}^{2} \int_{k_{n}}^{\infty} F(k) d k
$$

and this is proportional to $V^{2}{ }_{n}$. Hence, the relation

$$
V_{n}^{2} \propto \bar{V}^{2} \int_{k_{n}}^{\infty} F(k) d k
$$

holds, where $F(k)$ denotes a three-dimensional spectrum-function with respect to wave-number $k$. On the other hand, K. NAITo (1959) has shown that if the threedimensional spectrum decreases in proportion to $k^{-q}$ due to the increase of $k$ within the range of a very large wave-number, two- and one-dimensional spectra also have the same form. Hence the relation (3.16) may be considered to be valid for onedimension too, but the range over which it holds is different according to the direction, that is, the size of the apparent effectively largest eddy (the largest eddy in the apparent inertial subrange; hereafter the word "apparent" is used for the one-dimensional treatment) differs according to the direction. According to the results with respect to one-dimension thus far observed in the natural atmosphere, an apparent inertial subrange has been recognized to exist, and many one-dimensional mean eddies obtained from various actual measurements have been recognized to exist within this apparent inertial subrange.

Therefore, let us now represent the size and velocity of the mean eddy in the idirection by $\Lambda_{m i}$ (corresponding wave-number is $k_{m i}$ ) and $V_{m i}$, respectively, and then the total energy in the $\mathrm{i}$-direction of all eddies with wave-numbers larger than $k_{m i}$ is proportional to

$$
\bar{u}^{2} \int_{k_{m i}}^{\infty} F_{1}\left(k_{i}\right) d k_{i}, \quad\left(\begin{array}{c}
i=x, y, z \\
u_{x}=u, u_{y}=v, u_{z}=w
\end{array}\right),
$$

where $F_{1}\left(k_{i}\right)$ denotes one-dimensional energy spectrum-function with respect to onedimensional wave-number $k_{i}$.

On the other hand, we now denote the size components of an eddy in the $x, y, z$ directions by $\Lambda_{x}, \Lambda_{y}$ and $\Lambda_{z}$, respectively, and the velocity components of its eddy by $V_{x}, V_{y}$ and $V_{z}$, respectively. Then it may be considered that the ratio of $\Lambda_{x}: \Lambda_{y}$ : $\Lambda_{z}$ takes a constant value and so with the ratio of $V_{x}: V_{y}: V_{z}$, as E. Inoue (1962) has reported in the monthly regular meeting of the Meteorological Society of Japan. 
Hence the one-dimensional case may be dealt with in the same way as in the threedimensional case described above. Therefore, the total energy contained in $V_{m i}$ is proportional to $V^{2}{ }_{m i}$ and the integration of energy contained in all eddies smaller than $\Lambda_{m i}$ is proportional to $V_{m i}^{2}$, and the relation

$$
V^{2}{ }_{m i} \propto \bar{u}^{2} \int_{k_{m i}}^{\infty} F_{1}\left(k_{i}\right) d k_{i}
$$

may be obtained. But as the size of the apparent effectively largest eddy differs according to the direction as mentioned above, the sizes of mean eddies in each direction of $x, y$ and $z$ are different.

Let us now denote the size and velocity of the mean eddy in the i-direction of the model flow by $\Lambda_{m i M}$ and $V_{m i M}$, respectively, and those of the natural flow by $\Lambda_{m i N}$ and $V_{m i N}$, respectively. When the observation time is not so long, the apparent size of the mean eddy observed during that observation time may be considered to belong to the apparent inertial subrange. Now let the one-dimensional energy spectrumfunction in this intermediate range be represented by

$$
\begin{array}{ll}
F_{1}\left(k_{i}\right)=F_{1}\left(k_{0 i}\right)\left(\frac{k_{i}}{k_{0 i}}\right)^{-q} . & \text { for the model flow, } \\
F_{1}^{\prime}\left(k_{i}^{\prime}\right)=F_{1}^{\prime}\left(k_{0 i}^{\prime}\right)\left(\frac{k_{i}^{\prime}}{k_{0 i}^{\prime}}\right)^{-q} \quad \text { for the natural flow, }
\end{array}
$$

respectively, where $F_{1}\left(k_{0 i}\right)$ denotes the value of the one-dimensional energy spectrumfunction at the wave-number $k_{0 i}$ corresponding to the size of the apparent effectively largest eddy $A_{0 i M}$ of the model flow and $F_{1}^{\prime}\left(k_{0 i}^{\prime}\right)$ denotes that at the wave-number $k^{\prime}{ }_{0 i}$ corresponding to the size of the apparent effectively largest eddy $\Lambda_{0 i N}$ of the natural flow, that is, the apparent rate of energy distributed to the apparent effectively largest eddy.

Then the following relations holds :

$$
\begin{aligned}
& V^{2}{ }_{m i M} \text { cs } \bar{u}^{2}{ }_{i M} \int_{k_{m i}}^{\infty} F_{1}\left(k_{0 i}\right)\left(\frac{k_{i}}{k_{0 i}}\right)^{-q} d k_{i} \quad \text { for the model flow, } \\
& \text { (3.21) } \quad V^{2}{ }_{m_{i N}} \text { cs } \bar{u}_{i N}^{2} \int_{k^{\prime}{ }_{m i}}^{\infty} F_{1}^{\prime}\left(k^{\prime}{ }_{0 i}\right)\left(\frac{k_{i}^{\prime}}{k_{0 i}^{\prime}}\right)^{-q} d k_{i}^{\prime} \quad \text { for the natural flow, }
\end{aligned}
$$

provided that $\zeta$ has the same value for the two cases, where $k_{m i}$ denotes the wavenumber corresponding to $\Lambda_{m i M}$, and $k_{m i}^{\prime}$ that corresponding to $\Lambda_{m i N}$.

Next, by dividing both sides of (3.20) and (3.21) by $U^{2}{ }_{\infty M}$ and $U^{2}{ }_{\infty N}$, respectively,

$$
\begin{aligned}
& \frac{V^{2}{ }_{m i M}}{U^{2}{ }_{\infty M}} \leadsto \frac{\bar{u}^{2}{ }_{i M}}{U^{2}{ }_{\infty M}} \int_{k_{m i}}^{\infty} F_{1}\left(k_{0 i}\right)\left(\frac{k_{i}}{k_{0 i}}\right)^{-q} d k_{i}, \\
& \frac{V^{2}{ }_{m i N}}{U^{2}{ }_{\infty N}} \leadsto \frac{\bar{u}^{2}{ }_{i N}}{U^{2}{ }_{\infty N}} \int_{k^{\prime}{ }_{m i}}^{\infty} F_{1}^{\prime}\left(k_{0 i}^{\prime}\right)\left(\frac{k_{i}^{\prime}}{k_{0 i}^{\prime}}\right)^{-q} d k_{i}^{\prime},
\end{aligned}
$$

may be obtained. Hence, from (3.22) and (3.23), it follows that 


$$
\frac{V^{2}{ }_{m i M}}{U^{2}{ }_{\infty M}} / \frac{V^{2}{ }_{m i N}}{U^{2}{ }_{\infty N}}=\left(\frac{\bar{u}^{2}{ }_{i M}}{U^{2}{ }_{\infty M}} / \frac{\bar{u}^{2}{ }_{i N}}{U^{2}{ }_{\infty N}}\right) \frac{F_{1}\left(k_{0 i}\right)}{F_{1}^{\prime}\left(k^{\prime}{ }_{0 i}\right)} \frac{\int_{k_{m i}}^{\infty}\left(\frac{k_{i}}{k_{0 i}}\right)^{-q} d k_{i}}{\int_{k^{\prime}{ }_{m i}}^{\infty}\left(\frac{k_{i}^{\prime}}{k_{0 i}^{\prime}}\right)^{-q} d k^{\prime}{ }_{i}} .
$$

On the other hand, from the condition (3.11), that is,

$$
\frac{\bar{\imath}^{2}{ }_{i M}}{U_{\infty M}^{2}}=\frac{\bar{u}^{2}{ }_{i N}}{U_{\infty N}^{2}},
$$

the relation (3.24) becomes

$$
\frac{V_{m i M}^{2}}{U_{\infty M}^{2}}=\frac{F_{1}\left(k_{0 i}\right)}{F_{1}^{\prime}\left(k_{0 i}^{\prime}\right)}\left(\frac{k_{0 i}}{k_{0 i}^{\prime}}\right)^{q}\left(\frac{k_{m i}}{k_{m i}^{\prime}}\right)^{1-q}\left(\frac{V^{2}{ }_{m i N}}{U_{\infty N}^{2}}\right),
$$

as, in general, it may be considered that $q>1$ in an inertial subrange.

As

$$
\begin{array}{ll}
k_{0 i} \propto\left(\frac{L_{M}}{L_{N}}\right) \Lambda_{0 i M,}^{-1}, & k_{0 i}^{\prime} \propto \Lambda_{0 i N,}^{-1} \\
k_{m i} & \propto\left(\frac{L_{M}}{L_{N}}\right) \Lambda_{m i M,}^{-1} \quad
\end{array}
$$

may be satisfied, the relation (3.25) may be rewritten as

$$
\left(\frac{V_{m i M}}{U_{\infty M}}\right)^{2}=\frac{F_{1}\left(k_{0 i}\right)}{F_{1}^{\prime}\left(k_{0 i}^{\prime}\right)}\left(\frac{L_{M}}{L_{N}}\right)\left(\frac{\Lambda_{0 i N}}{\Lambda_{0 i M}}\right)^{q}\left(\frac{\Lambda_{m i N}}{\Lambda_{m i M}}\right)^{1-q}\left(\frac{V_{m i N}}{U_{\infty N}}\right)^{2},
$$

so that

$$
\frac{V_{m i M}}{U_{\infty M}}=\left[\frac{F_{1}\left(k_{0 i}\right)}{F_{1}^{\prime}\left(k_{0 i}^{\prime}\right)}\right]^{\frac{1}{2}}\left(\frac{\Lambda_{0 i N}}{\Lambda_{0 i M}}\right)^{\frac{q}{2}}\left(\frac{\Lambda_{m i N}}{\Lambda_{m i M}}\right)^{\frac{1-q}{2}}\left(\frac{L_{M}}{L_{N}}\right)^{\frac{1}{2}}\left(\frac{V_{m i N}}{U_{\infty N}}\right),
$$

may be obtained: Hence putting

$$
\left[\frac{F_{1}\left(k_{0 i}\right)}{F_{1}^{\prime}\left(k_{0 i}^{\prime}\right)}\right]^{\frac{1}{2}}\left(\frac{\Lambda_{0 i N}}{\Lambda_{0 i M}}\right)^{\frac{q}{2}}\left(\frac{\Lambda_{m i N}}{\Lambda_{m i M}}\right)^{\frac{1-q}{2}}\left(\frac{L_{M}}{L_{N}}\right)^{\frac{1}{2}}=\sigma,
$$

the relation (3.28) may be reduced to

$$
\frac{V_{m i M}}{V_{m i N}}=\sigma\left(\frac{U_{\infty M}}{U_{\infty N}}\right) .
$$

On the other hand, as each eddy diffusion coefficient at each corresponding place of model and natural flows may be given by

$$
\begin{aligned}
& K_{i M}=\beta \Lambda_{m i M} V_{m i M}, \\
& K_{i N}=\beta \Lambda_{m i N} V_{m i N},
\end{aligned}
$$

respectively, where $\beta$ denotes a universal constant, the condition of identity for the eddy Reynolds number, (3.12), may be represented by 


$$
\frac{L_{M} U_{\infty M}}{\Lambda_{m i M} V_{m i M}}=\frac{L_{N} U_{\infty N}}{\Lambda_{m i N} V_{m i N}} .
$$

Hence, inserting (3.30) into (3.33), we may obtain

$$
\frac{\Lambda_{m i M}}{\Lambda_{m i N}}=\frac{1}{\sigma}\left(\frac{L_{M}}{L_{N}}\right) .
$$

Then, from (3.29) and (3.34)

$$
\left(\frac{\Lambda_{m i M}}{\Lambda_{m i N}}\right)^{-(1+q)}=\left[\frac{F_{1}\left(k_{0 i}\right)}{F_{1}^{\prime}\left(k_{0 i}^{\prime}\right)}\right]\left(\frac{\Lambda_{0 i M}}{\Lambda_{0 i N}}\right)^{-q}\left(\frac{L_{M}}{L_{N}}\right)^{-1} .
$$

Since it may be considered that $q=5 / 3$ over the inertial subrange, (3.35) may be written as

$$
\frac{\Lambda_{m i M}}{\Lambda_{m i N}}=\left[\frac{F_{1}\left(k_{0 i}\right)}{F_{1}^{\prime}\left(k_{0 i}^{\prime}\right)}\right]^{-\frac{3}{8}}\left(\frac{\Lambda_{0 i M}}{\Lambda_{0 i N}}\right)^{\frac{5}{8}}\left(\frac{L_{M}}{L_{N}}\right)^{\frac{3}{8}}
$$

and (3.29) may be written as

$$
\sigma=\left[\frac{F_{1}\left(k_{0 i}\right)}{F_{1}^{\prime}\left(k^{\prime}{ }_{0 i}\right)}\right]^{\frac{1}{2}}\left(\frac{\Lambda_{0 i M}}{\Lambda_{0 i N}}\right)^{-\frac{5}{6}}\left(\frac{\Lambda_{m i M}}{\Lambda_{m i N}}\right)^{\frac{1}{3}}\left(\frac{L_{M}}{L_{N}}\right)^{\frac{1}{2}} .
$$

On the other hand, the size of the mean eddy for an observation time $T_{*}$ is defined by

$$
\Lambda_{T *}=U \int_{0}^{T_{0}} R_{T *}(t) d t
$$

where $U$ is the mean wind velocity, $R_{T_{*}}(t)$ denotes the Eulerian correlation and $T_{0}$ means the time in which $R_{T *}(t)$ reduces to zero. Since it may be considered that

$$
R_{T *}(t)=1-\left(\frac{t}{T_{0}}\right)^{\frac{2}{3}} \quad t \leqq T_{0}
$$

hold over the apparent inertial subrange, it follows from (3.38) and (3.39) that

$$
\Lambda_{T *}=\frac{2}{5} T_{0} U
$$

In the above-mentioned relation, $T_{0} U$ means the size of the apparent effectively largest eddy in the i-direction, so that

$$
\frac{\Lambda_{m i M}}{\Lambda_{m i N}}=\frac{\Lambda_{0 i M}}{\Lambda_{0 i N}} .
$$

Hence, from (3.37),

$$
\sigma=\left[\frac{F_{1}\left(k_{0 i}\right)}{F_{1}^{\prime}\left(k_{0 i}^{\prime}\right)}\right]^{\frac{1}{2}}\left(\frac{\Lambda_{m i M}}{\Lambda_{m i N}}\right)^{-\frac{1}{2}}\left(\frac{L_{M}}{L_{N}}\right)^{\frac{1}{2}}
$$

Thus in this case there is the following relation between the sizes of both mean eddies: 


$$
\frac{\Lambda_{m i M}}{\Lambda_{m i N}}=\left[\frac{F_{1}\left(k_{0 i}\right)}{F_{1}^{\prime}\left(k_{0 i}^{\prime}\right)}\right]^{-1}\left(\frac{L_{M}}{L_{N}}\right) .
$$

Therefore, in this case it follows from (3.42) that

$$
\sigma=\frac{F_{1}\left(k_{0 i}\right)}{F_{1}^{\prime}\left(k_{0 i}^{\prime}\right)} .
$$

That is, when the relation (3.43) is satisfied between the size of the mean eddy of the model flow and that of the natural flow, the conditions of both identity of the intensities of turbulence and identity of the eddy Reynolds numbers may be simultaneously satisfied.

On the other hand, from the remaining condition (3.14), that is, the identity for the Froude number, it follows that

$$
\frac{V_{m i M}}{V_{m i N}}=\sigma^{\frac{3}{2}}\left(\frac{\Lambda_{m i M}}{\Lambda_{m i N}}\right)^{\frac{1}{2}} .
$$

Hence, in order that the three conditions previously described may be simultaneously satisfied the relation (3.45) shoud be satisfied among the sizes and velocities of the mean eddies of model and natural flows. On the other hand, from (3.34) and (3.45) it follows that

$$
\frac{V_{m i M}}{V_{m i N}}=\left(\frac{L_{M}}{L_{N}}\right)^{\frac{3}{2}}\left(\frac{\Lambda_{m i M}}{\Lambda_{m i N}}\right)^{-1} .
$$

That is, in this case, when the above-mentioned relation holds among the sizes and velocities of the apparent mean eddies in the i-direction of model and natural flows, the following three conditions, that is, identity for the intensity of turbulence, the eddy Reynolds number and the Froude number, can be simultaneously satisfied and the mean flow patterns of the two flows should be similar. But in this case, as

$$
\begin{aligned}
& \frac{\Lambda_{m i M}}{\Lambda_{m i N}}=\frac{1}{\sigma}\left(\frac{L_{M}}{L_{N}}\right), \\
& \frac{V_{m i M}}{V_{m i N}}=\sigma^{\frac{3}{2}}\left(\frac{\Lambda_{m i M}}{\Lambda_{m i N}}\right)^{\frac{1}{2}},
\end{aligned}
$$

are satisfied, from these two relations

$$
\frac{V_{m i M}}{V_{m i N}}=\sigma\left(\frac{L_{M}}{L_{N}}\right)^{\frac{1}{2}}
$$

may be obtained. On the other hand in this case as each one-dimensional energy spectrum-function of model and natural flows is represented by

$$
\begin{aligned}
& F_{1}\left(k_{i}\right)=F_{1}\left(k_{0 i}\right)\left(\frac{k_{i}}{k_{0 i}}\right)^{-\frac{5}{3}}, \\
& F_{1}^{\prime}\left(k_{i}^{\prime}\right)=F_{1}^{\prime}\left(k_{0 i}^{\prime}\right)\left(\frac{k_{i}^{\prime}}{k_{0 i}^{\prime}}\right)^{-\frac{5}{3}},
\end{aligned}
$$


respectively, at each corresponding place, it may be considered that $V_{n} \backsim \varepsilon^{\frac{1}{3}} \Lambda_{n}^{\frac{1}{3}}$ holds between size and velocity of an eddy within the inertial subrange. Hence, if the average rate of dissipation of energy per unit mass and unit time of the natural flow is denoted by $\varepsilon_{N}$, and that per reduced mass and reduced time of the corresponding model flow by $\varepsilon_{M}$, the following relations will hold:

$$
\begin{array}{ll}
V_{m i M} \propto \varepsilon_{M}^{\frac{1}{3}} \Lambda^{\frac{1}{3}}{ }_{m i M} & \text { for the model flow, } \\
V_{m i N} \propto \varepsilon_{N}^{\frac{1}{3}} \Lambda^{\frac{1}{3}}{ }_{m i N} & \text { for the natural flow. }
\end{array}
$$

So that from these two relations

$$
\frac{V_{m i M}}{V_{m i N}}=\left(\frac{\varepsilon_{M}}{\varepsilon_{N}}\right)^{\frac{1}{3}}\left(\frac{\Lambda_{m i M}}{\Lambda_{m i N}}\right)^{\frac{1}{3}}
$$

may be obtained. Hence from (3.34), (3.47) and (3.48) it follows that

$$
\frac{\varepsilon_{M}}{\varepsilon_{N}}=\sigma^{4}\left(\frac{L_{M}}{L_{N}}\right)^{\frac{1}{2}}=\left[\frac{F_{1}\left(k_{0 i}\right)}{F_{1}^{\prime}\left(k_{0 i}^{\prime}\right)}\right]^{4}\left(\frac{L_{M}}{L_{N}}\right)^{\frac{1}{2}} .
$$

That is, in this case the relation (3.49) must be satisfied among the quantities at each corresponding place of model and natural flows. Hence, the mean flow patterns of both cases are similar for wind velocities $U_{\infty M}$ and $U_{\infty N}$ which satisfy the relation

$$
\frac{U_{\infty M}}{U_{\infty N}}=\left(\frac{L_{M}}{L_{N}}\right)^{\frac{1}{2}}
$$

provided that (3.49) is satisfied. But similarity of structure of the turbulence cannot be expected.

A number of experiments have been done with a view to making the Froude number of the model flow identical with that of the natural flow, and resulted in the mean flow patterns of the two flows becoming approximately similar. When the order of the gravity term is fairly large in comparison with those of the other terms, similarity of the mean flow patterns of the two flows may be, of course, expected from the condition of identity for the Froude number only, but it is found from the result obtained in the present section that this similarity may be also expected in the case where the order of the gravity term is comparable with those of the other terms.

\section{The case in which turbulence is taken into account but the effect of gravity is not considered}

When a phenomenon in a relatively small region is dealt with, the motions in the $x$ and $y$ directions do not depend on gravity, and in a strong wind $W$ may be considered to be negligibly small in comparison with $U$ and $V$. Furthermore variations of both static pressure and $\bar{w}^{2}$ with height are fairly small and may be neglected, so that the equation of motion in the $z$ direction may be left out of consideration, and then the equations of motion may be given by

$$
\frac{\partial U}{\partial t}+\frac{\partial}{\partial x}\left(U^{2}\right)+\frac{\partial}{\partial x}\left(\bar{u}^{2}\right)+\frac{\partial}{\partial y}(U V)
$$




$$
\begin{aligned}
& =-\frac{1}{\rho} \frac{\partial p}{\partial x}+\frac{\partial}{\partial y}\left(K_{y} \frac{\partial U}{\partial y}\right)+\frac{\partial}{\partial z}\left(K_{z} \frac{\partial U}{\partial z}\right), \\
& \frac{\partial V}{\partial t}+\frac{\partial}{\partial x}(U V)+\frac{\partial}{\partial y}\left(V^{2}\right)+\frac{\partial}{\partial y}\left(\bar{v}^{2}\right) \\
& =-\frac{1}{\rho} \frac{\partial p}{\partial y}+\frac{\partial}{\partial x}\left(K_{x} \frac{\partial V}{\partial x}\right)+\frac{\partial}{\partial z}\left(K_{z} \frac{\partial V}{\partial z}\right) .
\end{aligned}
$$

Therefore, in this case it is suitable to consider the following two conditions, that is, identity for the intensity of turbulence and that for the eddy Reynolds number, as the conditions for similarity. That is, the conditions corresponding to (3.11) and (3.12) may be adopted. In this case we may consider the two cases about structure of turbulence, that is, non-similar and similar.

\section{(1) The case in which the structures of the two flows of model and prototype are not similar.}

In this case, as previously described, if

$$
\begin{aligned}
& \frac{A_{m i M}}{\Lambda_{m i N}}=\frac{1}{\sigma}\left(\frac{L_{M}}{L_{N}}\right), \\
& \frac{V_{m i M}}{V_{m i N}}=\sigma\left(\frac{U_{\infty M}}{U_{\infty N}}\right)
\end{aligned}
$$

can be satisfied, the condition of identity of the intensities of turbulence and that of the eddy Reynolds numbers are simultaneously satisfied. But each energy spectrumfunction of model and natural flows is also expressed, respectively, by

$$
\begin{aligned}
& F_{1}\left(k_{i}\right)=F_{1}\left(k_{0 i}\right)\left(\frac{k_{i}}{k_{0 i}}\right)^{-\frac{5}{3}} \\
& F_{1}^{\prime}\left(k_{i}^{\prime}\right)=F_{1}^{\prime}\left(k_{0 i}^{\prime}\right)\left(\frac{k_{i}^{\prime}}{k_{0 i}^{\prime}}\right)^{-\frac{5}{3}}
\end{aligned}
$$

and

$$
\sigma=\frac{F_{1}\left(k_{0 i}\right)}{F_{1}^{\prime}\left(k_{0 i}^{\prime}\right)}
$$

The restriction that

$$
\frac{U_{\infty M}}{U_{\infty N}}=\left(\frac{L_{M}}{L_{N}}\right)^{\frac{1}{2}}
$$

has to be satisfied does not appear in this case.

In this case it may be considered that the relation

$$
V_{n} \propto \varepsilon^{\frac{1}{3}} A_{n}^{\frac{1}{3}}
$$

holds between size and velocity of an eddy within the inertial subrange. Therefore, as previously described, 


$$
\frac{V_{m i M}}{V_{m i N}}=\left(\frac{\varepsilon_{M}}{\varepsilon_{N}}\right)^{\frac{1}{3}}\left(\frac{\Lambda_{m i M}}{\Lambda_{m i N}}\right)^{\frac{1}{3}}
$$

may be obtained. Inserting (4.3) and (4.4) into the above-mentioned relation,

$$
\frac{U_{\infty M}}{U_{\infty N}}=\sigma^{-\frac{4}{3}}\left(\frac{\varepsilon_{M}}{\varepsilon_{N}}\right)^{\frac{1}{3}}\left(\frac{L_{M}}{L_{N}}\right)^{\frac{1}{3}}
$$

Furthermore, inserting a value of $\sigma$ into this relation,

$$
\frac{U_{\infty M}}{U_{\infty N}}=\left(\frac{\varepsilon_{M}}{\varepsilon_{N}}\right)^{\frac{1}{3}}\left[\frac{F_{1}\left(k_{0 i}\right)}{F_{1}^{\prime}\left(k_{0 i}^{\prime}\right)}\right]^{-\frac{4}{3}}\left(\frac{L_{M}}{L_{N}}\right)^{\frac{1}{3}}
$$

As known from this relation, even if the reduced scale of the model $L_{M} / L_{N}$ is determined, the wind velocity of the model wind $U_{\infty_{M}}$ corresponding to that of the natural wind $U_{\infty_{N}}$ is not uniquely determined but further depends on the ratio of the rates of dissipation of energy and the ratio of the values of energy spectrum-function at each apparent effectively largest eddy of both flows. But if $\left(\varepsilon_{M} / \varepsilon_{N}\right)^{\frac{1}{3}}\left[F_{1}\left(k_{0 i}\right) / F_{1}^{\prime}\left(k_{0 i}^{\prime}\right)\right]^{-\frac{4}{3}}$ remains constant independent of places, similarity may be expected between the mean flow patterns of model and natural flows for the wind velocity satisfying the relation (4.6).

\section{(2) The case in which the structures of turbulence of the two flows of model and prototype are similar.}

In this case, as previously described, $\sigma=1$ and

$$
\begin{aligned}
& \frac{\Lambda_{m i M}}{\Lambda_{m i N}}=\frac{\Lambda_{0 i M}}{\Lambda_{0 i N}}=\frac{L_{M}}{L_{N}}, \\
& \frac{V_{m i M}}{V_{m i N}}=\frac{U_{\infty M}}{U_{\infty N}}, \\
& F_{1}\left(k_{0 i}\right)=F_{1}^{\prime}\left(k_{0 i}^{\prime}\right)
\end{aligned}
$$

may hold, each one-dimensional energy spectrum-function of the two cases is given by

$$
\begin{aligned}
& F_{1}\left(k_{i}\right)=F_{1}\left(k_{0 i}\right)\left(\frac{k_{i}}{k_{0 i}}\right)^{-\frac{5}{3}} \\
& F_{1}^{\prime}\left(k_{i}^{\prime}\right)=F_{1}^{\prime}\left(k_{0 i}^{\prime}\right)\left(\frac{k_{i}^{\prime}}{k_{0 i}^{\prime}}\right)^{-\frac{5}{3}}
\end{aligned}
$$

respectively, and

$$
V_{n} \operatorname{cs} \varepsilon^{\frac{1}{3}} \Lambda_{n}^{\frac{1}{3}}
$$

holds between size and velocity of an eddy within the inertial subrange.

When the natural flow is compared with the model flow, the unit area of the natural flow corresponds to the area of $\left(L_{M} / L_{N}\right)^{2}$ of the model flow, the unit time corresponds to $t_{M} / t_{N}$, and hence the unit mass of the natural flow corresponds to the reduced mass of $\left(L_{M} / L_{N}\right)^{2}\left(U_{M} / U_{N}\right)$ of the model flow. So that (unit mass) $\times$ (unit 
time) of the natural flow corresponds to $\left(L_{M} / L_{N}\right)^{2}\left(U_{M} / U_{N}\right)\left(t_{M I} / t_{N}\right)$ of the model flow. On the other hand, since

$$
t_{M}=\frac{L_{M}}{U_{M}}, \quad t_{N}=\frac{L_{N}}{U_{N}},
$$

then

$$
\frac{U_{M}}{U_{N}}=\frac{L_{M}}{L_{N}} \cdot \frac{t_{N}}{t_{M}}
$$

Hence, after all, (unit mass) $\times$ (unit time) of the natural flow corresponds to $\left(L_{M} / L_{N}\right)^{3}$ of the model flow.

Then, if the average rate of dissipation of energy per unit mass and unit time of the natural flow is denoted by $\varepsilon_{N}$,

$$
\varepsilon_{N}=A \nu \int k^{\prime 2} F^{\prime}\left(k^{\prime}\right) d k^{\prime}
$$

where $k^{\prime}$ denotes the wave-number per unit length of the natural flow.

Next, if the wave-number per unit length of the model flow is denoted by $k$ and the structure of turbulence of the model flow is similar to that of the natural flow,

$$
k \frac{L_{M}}{L_{N}}=k^{\prime}
$$

On the other hand, if the average rate of dissipation of energy per unit mass and unit time of the model flow is denoted by $\varepsilon$,

$$
\varepsilon=A \nu \int k^{2} F(k) d k
$$

By inserting (4.11) into (4.12) we may obtain

$$
\varepsilon=A \nu \int k^{\prime 2}\left(\frac{L_{N}}{L_{M}}\right)^{2} F^{\prime}\left(k^{\prime}\right)\left(\frac{L_{N}}{L_{M}}\right) d k^{\prime}=\left(\frac{L_{N}}{L_{M}}\right)^{3} A \nu \int k^{\prime 2} F^{\prime}\left(k^{\prime}\right) d k^{\prime} .
$$

Hence

$$
\varepsilon\left(\frac{L_{M}}{L_{N}}\right)^{3}=A \nu \int k^{\prime 2} F^{\prime}\left(k^{\prime}\right) d k^{\prime}=\varepsilon_{N}
$$

and $\varepsilon\left(L_{M} / L_{N}\right)^{3}$ means the average rate of dissipation of energy per reduced mass and reduced time of the model flow $\varepsilon_{M}$. Thus it follows that

$$
\varepsilon_{M}=\varepsilon_{N} .
$$

Therfore, by inserting (4.9) and (4.13) into (4.6) we may obtain

$$
\frac{U_{\infty M}}{U_{\infty N}}=\left(\frac{L_{M}}{L_{N}}\right)^{\frac{1}{3}}
$$

between the reduced scale of the model and that of wind velocity, which has already 
been proposed in our previous paper (Part I) and experimentally verified in Part III.

But it needs to be noted here that the energy spectrum-function previously described represents only that within the inertial subrange (intermediate range), and it has each another form within each range of the largest eddy and the smallest eddy ranges. Hence it must be noted that similarity of structure of turbulence described here is valid in the meaning of approximate similarity.

For example, when the energy dissipation due to the molecular viscosity is considered, this is proportional to $\nu k^{2}$. That is, the energy dissipation rapidly increases with increase of $k$ (that is, corresponding to decrease in eddy size). When the model flow is compared with the natural flow, the size of an eddy in the model flow is $L_{M} / L_{N}$ times as large as its counterpart in the natural flow even if their wave-numbers are the same. But, on the other hand, it may be considered that the size of the smallest eddy in the natural flow differs little from that in the model flow. Hence it will be considered that, in the case where the reduced scale of the model is large, no wave-number larger than the one corresponding to a certain wave-number in the natural flow can be found in the model flow, while wave-numbers larger than it are found in the natural flow. Therefore, it must be noted that similarity of structure of turbulence does not hold in the strict sense and the word "similarity" in the present paper is used in the meaning of "approximate similarity". Accuracy of similarity decreases with increases of the reduced scale of the model.

\section{The case in which the condition of identity for the intensity of turbulence is left out of consideration}

Let us now consider a simple case where the direction of the general flow is parallel to the $x$-axis and its velocity varies to the $z$-axis, that is, $U=U(z), V=W=0$ and each gradient of $\bar{u}^{2}, \bar{v}^{2}, \bar{v}^{2}$ may be neglected. The property of this case is that there is not the condition of identity for the intensity of turbulence. A flow near the ground surface is on the whole closely allied to this state.

In this case the equation of motion governing the general flow, may be given by

$$
\frac{\partial U}{\partial t}=-\frac{1}{\rho} \frac{\partial p}{\partial x}+\frac{\partial}{\partial z}\left(K_{z} \frac{\partial U}{\partial z}\right) \text {. }
$$

The above equation may be transformed into the non-dimensional equation, in the way previously described, as follows:

$$
\frac{\partial U^{\prime}}{\partial t^{\prime}}=-\frac{1}{\rho^{\prime}} \frac{\partial p^{\prime}}{\partial x^{\prime}}+\frac{\partial}{\partial z^{\prime}}\left\{\left(\frac{K_{z}}{L U_{\infty}}\right) \frac{\partial U^{\prime}}{\partial z^{\prime}}\right\} .
$$

Hence the condition for similarity in this case is that the relation

$$
\frac{K_{z M}}{L_{M} U_{\infty M}}=\frac{L_{z N}}{L_{N} U_{\infty N}}
$$

is satisfied, and this means that the eddy Reynolds number of the model flow is identical with that of the natural flow and the condition of identity for the intensity of turbulence does not appear. That is, it is not always necessary that 


$$
\frac{\bar{w}_{M}^{2}}{U^{2}{ }_{\infty M}}=\frac{\bar{w}_{N}^{2}}{U^{2}{ }_{\infty N}} .
$$

Hence, putting

$$
\frac{\bar{w}_{M}^{2}}{U^{2}{ }_{\infty M}} / \frac{\bar{w}^{2}}{U^{2}{ }_{\infty N}}=\alpha^{2}
$$

and representing, respectively, each one-dimensional energy spectrum-function within each apparent inertial subrange of the two flows by

$$
\begin{aligned}
& F_{1}\left(k_{z}\right)=F_{1}\left(k_{0 z}\right)\left(\frac{k_{z}}{k_{0 z}}\right)^{-\frac{5}{3}} \quad \text { for the model flow, } \\
& F_{1}^{\prime}\left(k_{z}^{\prime}\right)=F_{1}^{\prime}\left(k_{0 z}^{\prime}\right)\left(\frac{k_{z}^{\prime}}{k_{0 z}^{\prime}}\right)^{-\frac{5}{3}} \text { for the natural flow, }
\end{aligned}
$$

from (3.24)

$$
\frac{V^{2}{ }_{m z M}}{U_{\infty M}^{2}}=\alpha^{2} \sigma^{2}\left(\frac{V^{2}{ }_{m z N}}{U_{\infty N}^{2}}\right),
$$

that is,

$$
\frac{V_{m z M}}{U_{\infty M}}=\alpha \sigma\left(\frac{V_{m z N}}{U_{\infty N}}\right)
$$

may be obtained. But in this case

$$
\sigma=\frac{F_{1}\left(k_{0 z}\right)}{F_{1}^{\prime}\left(k_{0 z}^{\prime}\right)} .
$$

By inserting the relation (5.7) into the condition of identity for the eddy Reynolds number, we may obtain

$$
\frac{\Lambda_{m z M}}{\Lambda_{m z N}}=\alpha^{-1}\left[\frac{F_{1}\left(k_{0 z}\right)}{F_{1}^{\prime}\left(k_{0 z}^{\prime}\right)}\right]^{-1}\left(\frac{L_{M}}{L_{N}}\right) .
$$

As seen from this, the structures of turbulence are not similar. However, as the condition of identity for the eddy Reynolds number is satisfied, the mean flow patterns (wind profiles) are similar. An example for this case is similarity between a wind profile above the urban district in a typhoon and that above the model rough surface in the wind tunnel (cf. Part II).

In this case, as each eddy diffusion coefficient of model and natural flows may be represented, respectively, by

$$
\begin{aligned}
& K_{z M} \odot V_{m z M} \Lambda_{m z M} \odot \varepsilon_{M}^{\frac{1}{3}} \Lambda^{\frac{4}{3}}{ }_{m z M}, \\
& K_{z N} \odot V_{m z N} A_{m z N} \odot \varepsilon_{N}^{\frac{1}{3}} \Lambda^{\frac{4}{3}}{ }_{m z N},
\end{aligned}
$$

from $(5.3)$ 


$$
\frac{U_{\infty M}}{U_{\infty N}}=\left(\frac{\varepsilon_{M}}{\varepsilon_{N}}\right)^{\frac{1}{3}}\left(\frac{\Lambda_{m z M}}{\Lambda_{m z N}}\right)^{\frac{4}{3}}\left(\frac{L_{M}}{L_{N}}\right)^{-1}
$$

may be obtained. Then from (5.8) and the above relation it follows that

$$
\frac{U_{\infty M}}{U_{\infty N}}=\alpha^{-\frac{4}{3}}\left(\frac{\varepsilon_{M}}{\varepsilon_{N}}\right)^{\frac{1}{3}}\left[\frac{F_{1}\left(k_{0 z}\right)}{F_{1}^{\prime}\left(k_{0 z}^{\prime}\right)}\right]^{-\frac{4}{3}}\left(\frac{L_{M}}{L_{N}}\right)^{\frac{1}{3}}
$$

Therefore, if $\alpha^{-\frac{4}{3}}\left(\varepsilon_{M} / \varepsilon_{N}\right)^{\frac{1}{3}}\left[F_{1}\left(k_{0 z}\right) / F_{1}^{\prime}\left(k_{0 z}^{\prime}\right)\right]^{-\frac{4}{3}}$ always takes a constant value irrespective of place, both mean flow patterns are similar to each other, when the relation (5.10) is satisfied between the reduced scale of the model and that of wind velocity, but the structures of turbulence do not become similar, where

$$
\alpha=\frac{\sqrt{\bar{w}^{2} M}}{U_{\infty M}} / \frac{\sqrt{\bar{w}^{2} N}}{U_{\infty N}},
$$

and $\alpha$ denotes the ratio of the intensities of turbulence at corresponding places in model and natural flows. similar,

In this case, if the structures of turbulence, furthermore, become approximately

$$
\begin{gathered}
\sigma=1, \\
\frac{\Lambda_{m z M}}{\Lambda_{m z N}}=\frac{\Lambda_{0 z M}}{\Lambda_{0 z N}}=\frac{L_{M}}{L_{N}}, \\
F_{1}\left(k_{0 z}\right)=F_{1}^{\prime}\left(k_{0 z}^{\prime}\right),
\end{gathered}
$$

as previously described, then from (5.10)

$$
\frac{U_{\infty M}}{U_{\infty N}}=\alpha^{-\frac{4}{3}}\left(\frac{\varepsilon_{M}}{\varepsilon_{N}}\right)^{\frac{1}{3}}\left(\frac{L_{M}}{L_{N}}\right)^{\frac{1}{3}}
$$

and furthermore from (5.8) $\alpha=1$, and from (4.13) $\varepsilon_{M}=\varepsilon_{N}$. Thus the above-mentioned relation reduces to

$$
\frac{U_{\infty M}}{U_{\infty N}}=\left(\frac{L_{M}}{L_{N}}\right)^{\frac{1}{3}}
$$

On the other hand, this relation may be derived from another treatment. That is, the energy transferred from the general flow to the turbulence by the Reynolds stress is given by

$$
-\rho(\overline{u w}) \frac{\partial U}{\partial z}
$$

and this may be written as

$$
\rho K_{z}\left(\frac{\partial U}{\partial z}\right)^{2}
$$

And in order that the structure of turbulence may become approximately similar, the 
rate of energy transferred to the turbulence must be equal in both cases of model and prototype. That is,

$$
\rho_{M} K_{z M}\left(\frac{\partial U_{M}}{\partial z_{M}}\right)^{2}=\rho_{N} K_{z N}\left(\frac{\partial U_{N}}{\partial z_{N}}\right)^{2}
$$

should hold. This relation may be written by the non-dimensional quantities as follows, provided that $\rho_{M} \doteqdot \rho_{N}$,

$$
K_{z M} \frac{U^{2}{ }_{\infty M}}{L^{2}{ }_{M}}\left(\frac{\partial U^{\prime}}{\partial z^{\prime}}\right)^{2}=K_{z N} \frac{U^{2}{ }_{\infty N}}{L^{2}{ }_{N}}\left(\frac{\partial U^{\prime}}{\partial z^{\prime}}\right)^{2} .
$$

Hence

$$
K_{z M} \frac{U^{2}{ }_{\infty M}}{L^{2}{ }_{M}}=K_{z N} \frac{U^{2}{ }_{\infty N}}{L^{2}{ }_{N}}
$$

may be obtained. This may also be written as

$$
\Lambda_{m z M} V_{m z M} \frac{U^{2}{ }_{\infty M}}{L^{2}{ }_{M}}=\Lambda_{m z N} V_{m z N} \frac{U^{2}{ }_{\infty N}}{L^{2}{ }_{N}} .
$$

But, on the other hand, as previously described,

$$
\frac{\Lambda_{m z M}}{\Lambda_{m z N}}=\frac{L_{M}}{L_{N}}, \quad \frac{V_{m z M}}{V_{m z N}}=\frac{U_{\infty M}}{U_{\infty N}},
$$

so that the above-mentioned relation reduces to

$$
\frac{U_{\infty M}}{U_{\infty N}}=\left(\frac{L_{M}}{L_{N}}\right)^{\frac{1}{3}}
$$

\section{Summary}

In order to determine the state of flow, it is desirable that five quantities, that is, velocity components $\mathrm{u}, \mathrm{v}, \mathrm{w}$ and $p, \rho$ can be obtained in each point of a field of flow. And in order to obtain these five quantities five equations are required. The equations of motion, of continuity and of state satisfy this requirement. One may deal with these five equations and initial and boundary conditions in order to consider similarity of the two flows. But as no special conditions can be derived from initial and boundary ones, these five equations should be discussed for the present.

However, when the similarity problem with respect to the natural wind is dealt with, the effects of the rotation of the earth, gravity, the thermal stability of the atmosphere and pressure must be taken into account. The conditions for similarity will vary according to which of these effects are taken into account. Since the effect of the thermal stability of the atmosphere may be considered to be negligible in strong winds, it is here left out of consideration.

D. Fultz has proposed three conditions, that is, identity for the Reynolds number, for the Froude number and for the Rossby number, as the conditions for similarity in consideration of the effects of the rotation of the earth, gravity and molecular 
viscosity, but as far as only molecular viscosity has been considered, the condition of identity for the Reynolds number and that for the Froude number are not simultaneously satisfied except in the case where the reduced scale of a model is equal to 1, that is, the size of the model is identical with that of the prototype. Furthermore, in an atmospheric phenomenon of large scale both pressure and density vary with height. Hence, the equation of state should be naturally taken into account. But it seems very difficult at present to reproduce a state similar to that of the atmosphere in a model of small scale. Furthermore, turbulence has not been considered in this treatment. From these considerations it seems to be impossible to realize the modeling of FulTz.

Modelings of small-scale phenomena (local winds) in the cases in which turbulence is taken into account are summarized as follows :

\section{(1) The case where the effect of the gravity and the eddy viscosity are taken into account}

The condition for similarity in this case is formally that the identity for the intensity of turbulence, for the eddy Reynolds number and for the Froude number should be simultaneously satisfied. Then, the approximate similarity of mean flow patterns of the two flows may be expected for wind velocities $U_{\infty M}$ and $U_{\infty N}$ which satisfy the relation

$$
\frac{U_{\infty M}}{U_{\infty N}}=\left(\frac{L_{M}}{L_{N}}\right)^{\frac{1}{2}}
$$

provided that

$$
\frac{\varepsilon_{M I}}{\varepsilon_{N}}=\left[\frac{F_{1}\left(k_{0 i}\right)}{F_{1}^{\prime}\left(k_{0 i}^{\prime}\right)}\right]^{4}\left(\frac{L_{M}}{L_{N}}\right)^{\frac{1}{2}}
$$

is satisfied, but similarity of structure of turbulence cannot be expected.

\section{(2) The case where the effect of gravity is left out of consideration}

The condition for similarity in this case is that the identity for the intensity of turbulence and that for the eddy Reynolds number should be simultaneously satisfied. On the structure of turbulence the two cases (similar, non-similar) may be considered in this case. If $F_{1}\left(k_{i}\right)$ \& $k_{i}^{-\frac{5}{3}}$ holds within one-dimensional apparent inertial subrange, the mean flow patterns of both cases are similar for $U_{\infty M}$ and $U_{\infty N}$ which satisfy the relation

$$
\frac{U_{\infty M}}{U_{\infty N}}=\left(\frac{\varepsilon_{M}}{\varepsilon_{N}}\right)^{\frac{1}{3}}\left[\frac{F_{1}\left(k_{0 i}\right)}{F_{1}^{\prime}\left(k^{\prime}{ }_{0 i}\right)}\right]^{-\frac{4}{3}}\left(\frac{L_{M}}{L_{N}}\right)^{\frac{1}{3}}
$$

as far as

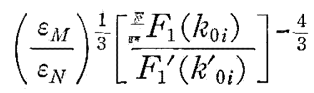

remains invariant irrespective of place. But similarity of structure of turbulence cannot be expected. Similarity of the structure of turbulence and that of mean flow 
patterns can be expected for wind velocities $U_{\infty M}$ and $U_{\infty N}$ which satisfy the relation

$$
\frac{U_{\infty M}}{U_{\infty N}}=\left(\frac{L_{M}}{L_{N}}\right)^{\frac{1}{3}}
$$

\section{(3) The case without the condition of identity for the intensity of turbulence}

A flow near the ground surface is on the whole closely allied to this state and the condition for similarity in this case is that the condition of identity for the eddy Reynolds number should be satisfied. The two cases (similar, non-similar) may also be considered and mean flow patterns of both cases are similar for wind velocities $U_{\infty M}$ and $U_{\infty N}$ which satisfy the relation

$$
\frac{U_{\infty M}}{U_{\infty N}}=\alpha^{-\frac{4}{3}}\left(\frac{\varepsilon_{M}}{\varepsilon_{N}}\right)^{\frac{1}{3}}\left[\frac{F_{1}\left(k_{0 z}\right)}{F_{1}^{\prime}\left(k_{0 z}^{\prime}\right)}\right]^{-\frac{4}{3}}\left(\frac{L_{M}}{L_{N}}\right)^{\frac{1}{3}}
$$

as far as

$$
\alpha^{-\frac{4}{3}}\left(\frac{\varepsilon_{M}}{\varepsilon_{N}}\right)^{\frac{1}{3}}\left[\frac{F_{1}\left(k_{0 z}\right)}{F_{1}^{\prime}\left(k_{0 z}^{\prime}\right)}\right]^{-\frac{4}{3}} \quad\left(\alpha=\frac{\sqrt{\bar{w}_{M}^{2}}}{U_{\infty M}} / \frac{\sqrt{\bar{w}^{2} N}}{U_{\infty N}}\right),
$$

remains invariant irrespective of place. On the other hand, the mean flow patterns of both cases are similar and further structure of turbulence becomes approximately similar for wind velocities $U_{\infty M}$ and $U_{\infty N}$ which satisfy the relation

$$
\frac{U_{\infty M}}{U_{\infty N}}=\left(\frac{L_{M}}{L_{N}}\right)^{\frac{1}{3}}
$$

Acknowledgement — The author wishes to express his sincere thanks to Dr. K. NAITO for his kind and instructive comments and criticisms on the present paper.

\section{References}

Bırкног, G., 1950: Hýdrodynamics: A study in logic, fact, and similitude. Princeton, Princeton Univ. Press, pp. 186.

F ULtz, D., 1951: Non-dimensional equations and modeling criteria for the atmosphere. J. Met., 8, 262-267.

Goi,dstein, S., 1938: Modern developments in fluid dynamics. Oxford Univ. Press, 1, pp. 330. Inoue, E., 1948: Natural wind vs. wind-canal flow. J. Japan Soc. for Appl. Mech., 1, 15-21. (in Japanese)

Inoue, E., 1951: Natural wind vs. wind-canal flow. J. Japan Soc. for Appl. Mech., 4, 27-30. (in Japanese)

Kolmogorow, A. N., 1941: The local structure of turbulence in incompressible viscous fluid for very large Reynolds numbers. C. R. (Doklady) Acad. Sci. URSS., 30, 301-305.

NaIto, K., 1959: One-, two- and three-dimensional observations and their spectra. Meteorology and Statistics, 10, No. 1, 36-43. (in Japanese)

Neмото, S., 1961: Similarity between natural wind in the atmosphere and model wind in a wind tunnel (I). Pap. Met. Geophys., 12, 30-52.

Nвмото, S., 1961: Similarity between natural wind in the atmosphere and model wind in a wind 
tunnel (II). Pap. Met. Geophys., 12, 117-128.

Nємото, S., 1961: Similarity between natural wind in the atmosphere and model wind in a wind tunnel (III). Pap. Met. Geophys., 12, 129-154.

Takahashi, K., 1944: Model experiment of atmospheric motion. J. Met. Soc. Japan, 22, 12-19. (in Japanese)

\section{局地 風の模型実 験について}

一第 4 報 理論的取扱飞対する補遺一

根本茂

まづはじめに，相似の問題を取报う際と考えなければならない事柄について述べ，一例として，大き なスケールの現像を取扱つた D. FuLTz の Modeling そついてその相似の条件を検討した。しかし，この Modeling の条件では, 通常使用されている風洞での模型実跉山不可能である。

つぎに，比晅的小さなスタールの現象（局地風）飞対する相似の問題を取扱つた。これに関しては既飞第

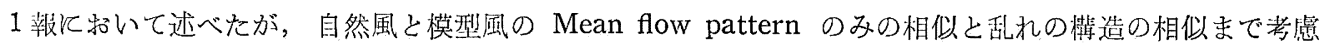
した場合の相似との間の相違とついての考察が充分でなかつたので，この点とついて更と検討した。その 結果,

（i）重力の影響ならびそ渦動粘性を考虑した場合。

自然風と模型風の対応する場所飞怙ける

乱れの強さ，

Eddy Reynolds number, 更炕また，

Froude number

がそれぞれ同時に一致することが相似の条件となり，更と乱れの構造とついて考学るとき，波数 $k_{i}$ (一次 元）飞対する乱れのエネルギースペクトル $F_{1}\left(k_{i}\right)$ (一次元) が見璐け上の Inertial subrange K拈いて $k_{i}{ }^{-\frac{5}{3}}$ K比例する限り,

$$
\frac{\varepsilon_{M}}{\varepsilon_{N}}=\left[\frac{F_{1}\left(k_{0 i}\right)}{F_{1}{ }^{\prime}\left(k^{\prime}\right)}\right]^{4}\left(\frac{L_{M}}{L_{N}}\right)^{\frac{1}{2}} \quad\left(\frac{L_{M}}{L_{N}}: \text { 模型の縮樂 }\right) .
$$

が場所飞関係なく近似的飞满足される場合

$$
\frac{U_{\infty M}}{U_{\infty N}}=\left(\frac{L_{M}}{L_{N}}\right)^{\frac{1}{2}}
$$

を満足するような風速 $U_{\infty M}, U_{\infty N}$ K刘して両者の Mean flow pattern の近似的相似が期待されるが， 乱れの構造は相似とならない。

(ii) 重力の影響を考えなくてよい場合。

雨者（自然風と模型風）の対応する場所炕粘ける

乱れの強さ，

Eddy Reynolds number

がそれぞれ同诗に一致することが相似の条件となり，見脚け上の Inertial subrange と括いて， $F_{1}\left(k_{i}\right)$ $\sim k_{i}{ }^{-\frac{5}{3}}$ なる限り, 


$$
\left(\frac{\varepsilon_{M}}{\varepsilon_{N}}\right)^{\frac{1}{3}}\left[\frac{F_{1}\left(k_{0 i}\right)}{F_{1}^{\prime}\left(k_{0 i}^{\prime}\right)}\right]^{-\frac{4}{3}}
$$

が場所関係なく近似的に一定の值をとるとき

$$
\frac{U_{\infty M}}{U_{\infty N}}=\left(\frac{\varepsilon_{M}}{\varepsilon_{N}}\right)^{\frac{1}{3}}\left[\frac{F_{1}\left(k_{0 i}\right)}{F_{1}{ }^{\prime}\left(k_{0 i}^{\prime}\right)}\right]^{-\frac{4}{3}}\left(\frac{L_{M}}{L_{N}}\right)^{\frac{1}{3}}
$$

なる関係を満足する風速 $U_{\infty M}, U_{\infty N}$ と対して両者の Mean flow pattern の近似的相似が期待されるが， 乱れの满造は相似飞ならない。

$$
\frac{U_{\infty M}}{U_{\infty N}}=\left(\frac{L_{M}}{L_{N}}\right)^{\frac{1}{3}}
$$

なる関倸を満足するような風速 $U_{\infty M}, U_{\infty_{N}}$ そ詨してのみ両者の Mean flow pattern ならびそ乱れの满 造の近似的相似が期待出来る。

(iii) 乱れの強さの一致の条件がない昜合。

中立状態飞特讨る地面附近の流れは一般にこの場合飞刘応する。この場合，

Eddy Reynolds number の一致

が相似の条件となる。而して，

$$
\alpha^{-\frac{4}{3}}\left(\frac{\varepsilon_{M}}{\varepsilon_{N}}\right)^{\frac{1}{3}}\left[\frac{F_{1}\left(k_{0 z}\right)}{F_{1}^{\prime}\left(k_{0 z}^{\prime}\right)}\right]^{-\frac{1}{3}} \quad\left(\alpha=\frac{\sqrt{\bar{w}^{2} M}}{U_{\infty M}} / \frac{\sqrt{\bar{w}^{2} N}}{U_{\infty N}}\right)
$$

が場所飞関係なく近似的に一定の值をとるとき

$$
\frac{U_{\infty M}}{U_{\infty N}}=\alpha^{-\frac{4}{3}}\left(\frac{\varepsilon_{M}}{\varepsilon_{N}}\right)^{\frac{1}{3}}\left[\frac{F_{1}\left(k_{0 z}\right)}{F_{1}^{\prime}\left(k_{0 z}^{\prime}\right)}\right]^{-\frac{4}{3}}\left(\frac{L_{M}}{L_{N}}\right)^{\frac{1}{3}}
$$

なる関係を満足するよろな風速 $U_{\infty M}, U_{\infty_{N}}$ 飞対して両者の Mean flow pattern のみの近似的相似が期 待出来,

$$
\frac{U_{\infty M}}{U_{\infty N}}=\left(\frac{L_{M}}{L_{N}}\right)^{\frac{1}{3}}
$$

なる関係を満足する風速 $U_{\infty M}, U_{\infty N}$ 飞対しては，更飞乱れの構造の近似的相似も期待出来る。 